\title{
Determining Relationship between Effective Leadership and Self-Awareness among Managers in South Africa
}

\author{
Mayuri Pillay $^{1}$ and Prof Muhammad Hoque ${ }^{2}$ \\ ${ }^{1}$ Postgraduate Student, University of KwaZulu-Natal, Durban, South Africa \\ ${ }^{2}$ Senior Research Associate, MANCOSA Graduate School of Business, South Africa
}

\begin{abstract}
The importance of self-awareness is pivotal to how we as individuals go about our daily lives - both as members of society and as a part of organizations. The way in which we lead, depends on the person we are. Studies into the linkage between self-awareness and leadership have not been given as much of the spotlight over the years. The aim of the study was to determine the relationship between effective leadership and self-awareness among managers in South Africa. This was a cross-sectional quantitative study conducted among 115 managers from a mortgagefinancing institution in South Africa. Data were collected using online platform and anonymous questionnaire was used. Results showed that majority of the managers had effective leadership criteria and they had good self-awareness. Correlation analysis found no significant relationship between effective leadership and self-awareness. Self-awareness tests should be utilized at a recruitment level and the importance of it should be driven throughout the organization.
\end{abstract}

Keywords: Leadership, self-awareness, organisation, manager, South Africa

\section{Introduction}

Leadership, which is one of the most important topics in human and social sciences, but traditionally one of the more poorly understood subject matter - two major reasons exists for this misunderstanding. Leadership firstly, solves the predicament of how collective effort should be structured - consequently this is the key to effectiveness of the organisations. Positive leadership enable organisations to thrive and prosper, when this happens the wellbeing of the incumbents are enhanced. Secondly, from a moral standpoint corrupt leaders can perpetrate abysmal misery on those affiliated with their sphere (Hogan \& Kaiser, 2005).

The importance of self-awareness both on a personal and professional level is of high importance to an individual with personal and professional aspirations. Individuals today are exposed unprecedented opportunities for growth, the presence of ambition and intellect can allow career advancement to the top of one's selected profession, irrespective of how and where the individual began. However, rising to the top and being effective leaders do not always go hand and hand. 
Literature that establishes the linkage between effective leadership and self-awareness is scarce. The importance between these two concepts demands attention, for it is essentially who we are that determines how (well) we lead. Concepts including communication, relationship building and emotional intelligence (EQ) have been raved about and have increasingly become part of corporate learning in order to boost organisational efficiency. Self-knowledge is a vast and exciting field which businesses are taking keen interest in - this due to the insight of the impact of intrapersonal skills on leadership. This study aims to determine the relationship between self-awareness and effective leadership among the managers from South Africa.

\section{Literature Review}

Human civilisation has throughout its path of development been exposed to wide-ranging social power distribution configurations. The essence of society is tightly connected with the process of group organisation, structure and the formation of the institution of power. The framework for the institution of power development in society can be traced back to the time when structured groups in society were categorised as the dominant minority and subordinate majority. The reality of humanism was that authority had become the fundamental starting point which separated society, created structure and created hierarchical patterns (Allayarova, Kalashnikova \& Moiseenko 2015).

\section{Leadership}

One of the most zealously reviewed socially influential process in humanity is leadership; the motive behind this lies with the dependency of the success of organisational, economic and political systems on the efficient and effective guidance of leaders. (Parris \& Peachey 2013). According to Lichtenstein et al. (2006); society is infatuated with leaders - these individuals who are in positions of power and who often subscribe to some form of grandeur and greatness. The traditional Western thinking behind leadership is that these individuals have the ability to plan the future, make rational decisions and execute the correct action in order to achieve said planned future.

Obiwuru et al. (2011) has propagated that the literature that surrounds leadership is of great importance in the organisational fields, this concept is one that has the most vibrant and influential impacts amongst the interaction between the individual and the organisation. To put into perspective, the ability of management to achieve the goals of the organisation is highly dependent on the abilities and skills of the leaders within the organisation. It is the leader who is tasked with not just creating motivating factors to unleash follower's potential but also meeting the goals of the organisation in order to fulfil the bigger and greater vision of the organisation.

Hogan and Kaiser (2005) argue that there are three ways that leadership can be described firstly it is possibly the single most vital issue in the social/human sciences which is real and vastly consequential. Secondly, leadership entails the performance of individuals, groups and organisations - positive leadership promotes team effectiveness and improved group performance, negative leadership can lead to the degradation of life quality for everyone associated with it. Lastly, the personality of a leader is a predictor of leadership; the way one leads is dependent on who the individual is. 
Stone, Russel and Patterson (2004) have stipulated that the various research studies undertaken throughout the years can ultimately identify two elements to leadership: the task or production element and a relational or people dimension. Leadership is according to Datta (2015), essentially the process where a group of individuals are influences to achieve shared goals, the fundamental function of leadership being to direct and change movement of an organization. Parris \& Peachey (2013) identify that the abilities used to inspire groups within an organization to work enthusiastically towards shared objectives is what leadership is all about.

The usual definitions of leadership flow along the lines of people who are entrusted with an organisation as well their units - as such leaders can be defined as people. It is good to note however that there are skills that are required to navigate through the status hierarchy of large bureaucratic organisations. People who rise up in organisations can be distinguished by the hard work, intellect, drive and ambition, political skill as well as luck but not always by a talent for leadership.

\section{Effective Leadership}

Being effective and efficient is one of the most important goals of any organisation, the optimisation of these two concepts can lead to positive impacts and results for the organisation, this being said the ability of an organisation to be efficient and effective is dependent on a leaders ability to perform effectively, that is to create goals and objectives that result in the organisational vision being achieved in the most efficient and effective manner.

Burke and Cooper (2006) make an important point by stating that effectiveness of leadership, although influenced by the personal characteristics of the leader ultimately is only effective it produces results. According to Yukl (2008) the performance of an organisation can be improved through leaderships influence over the factors of performance. An example of influence is how the leader interacts with stakeholders of the organisation (subordinates, peers and outsiders). Decisions revolving around management programs, systems and organisational make-up are another form where leaders can influence performance. Leaders can also influence organisational performance through the decision-making process around the competitive strategies that the organisation will pursue. These three forms of influence can and must be used together consistently in order for effective (strategic) leadership to occur.

According to Koenig (2011) leadership effectiveness involves the ability to motivate, monitor and engage in lifelong learning, Yukl (1999) propagates that leadership theories such as transformational and charismatic models attempt to shed light on effective leadership these however have their weaknesses. Lichtenstein et al. (2006) demonstrates that effective leadership does not necessarily rely soley on the leader himself. Stone, Russel and Patterson (2004) determined that the most effective leaders integrate their skills and the skills of their employees and that effective leadership is ultimately defined by two concepts: concern for people and the concern for output.

Just like the definition of leadership, the definition of effective leadership differs from one author to another according to Datta (2015). The majority of academics appraise the effectiveness of leaders in terms of results of the influence on a leader on a single person, group or organisation, Yukl (1999) stipulates that the most commonly used method of evaluating the 
effectiveness of a leader is to determine the degree that the goals of the organisation have been met through facilitation and the level at which the group's performance has been enhanced. Some general measures of how effective a leader is can be illustrated by looking at the organisations accounting figures such as the return on investments, sales figures, net profits, the margin of profits, market share and value just to name a few. Dorfman et. al (2012) suggests that a leader's perceived effectiveness is symbiosis between the expectations of the organisation and its constituents and the behaviour of a leader. Koenig (2011) simply define effective leadership as seen from the eyes of their followers. Effective leadership is ultimately doing the right things at the righ time in order to fulfil the vision of the organisation.

\section{Theories of Effective Leadership}

The Global Leadership and Organisational Behaviour Effectiveness Research (better known as the GLOBE) project was established in creating a universal model of leadership; however the dynamism of leadership and cultural differences in different areas of the world have shown that creating a common approach to leadership comes with great difficulty as universal approaches manifest differently in different regions. (Ayman \& Korabrik, 2010). This being said, the theories of leadership seek to clarify and categorise the dynamic makeup of leadership and the results of it.

The various ways in which an organisation is led has a different effect on the performance of the organisation, Schoel et al. (2011) stresses the importance of leadership styles by explaining that it is through the style of leadership that the group is guided and lines of responsibility are drawn. Fundamental studies on leadership focus on leader's behaviour - this includes the actions of a leader and what they do in order to achieve goals. The different styles and theories of leadership create differing power distributions within an organisation, it determines who's needs are met and how and guides the decision-making process throughout the value chain within an organisation. Mwithi (2015) promulgates that the importance of competent leadership is an essential function of any institution; he goes on to explain the significance of inspiring, motivating and persuading followers in achieving goals. Schoel et. al (2011) however goes on to explain that the success of leadership style is not just based on the leader himself but the context of the situation is very relevant and that different styles of leadership should be executed dependent on the situation itself.

\section{Self-Awareness}

Jabr (2012) claims that human-beings are more than the conscious - we are also aware of self. The development of favourable self-regulation and healthy relationships and experiences are born out of and driven from awareness. Awareness comprises of many different constituents, which include social, emotional and cognitive facets; cognitive awareness can be described as the ability of an individual to identify the structure of their cognisance, perception, understanding and thinking (Erden 2015).

Avolio and Gardner (2005) express the when individuals take cognisance of their own existence self-awareness occurs. They go on to describe self-awareness as a continuous process rather than a destination whereby an individual discovers himself. Self-awareness is according to Avolio and Gardner (2005) one of the key components of effective leadership. Views on 
how consciousness and self-awareness have been deliberated amongst scientists however a clear division can be made between the both. Consciousness is being aware of one's surroundings and physical body, self-awareness however recognises not only the consciousness but also understands that one's existence.

Self-awareness is highly relevant and cannot be overstated, according to Ashley \& ReiterPalmon (2012) numerous studies have theorized that human civilization has been born out of the capacity to self-reflect. They go on further to attribute technological advancements and cultural growth to stem from the capacity of individuals to think symbolically, logically and complexly about the self and changes required to make the future a better place.

Self-awareness has been adopted under various academic disciplines, which suggests that the concept of self-awareness can be explained in a number of areas. According to Sadri (2012) self-awareness is one of the personal competencies of emotional intelligence (the skill to selfmotivate and overcome challenges, to control short-term impulses in order to achieve delayed but more meaningful rewards, the regulation of one's temperaments, ability to control one's thinking, to sympathise with others and be optimistic.

Definitions vary however self-awareness can essentially be characterised by an inner process of appraisal in which individuals make self/standard assessments in order to become better individuals through improved knowledge of the self. (Ashley \& Reiter-Palmon 2012). Selfawareness refers to an individual's ability to become the focus of one's own attention, this happens when the individual paying attention to the internal occurrences by reflecting within and processing the information gathered from within. (Morin 2006)

Goleman (2004) defines self-awareness as an individual's capability to identify and comprehend their own moods, emotions and drivers as well as the effect that they have on others. Hernandez et al. (2015) agrees with this definition and stipulates that self-awareness comprises of inner and outward elements with lead to stable traits within an individual through the knowledge of one's internal resources which is at the forefront of self-regulation. Taylor, Wang \& Zhan (2012) define self-awareness the process of self-appraisal that uses inner and outer information in order to evaluate the self as well as how other's perceive the self.

Taylor, Wang and Zhan (2012) identify two pivotal constituents of self-awareness: the understanding of oneself and the ability to estimate the perceptions that others have of oneself. The first component which identifies the resources that one has which includes the knowledge of the individuals strengths and weaknesses, internal vision for life, fundamental morals and beliefs, factors that motivate the individual as well as the individuals personality characteristics. It effectively being knowledgeable of one's own makeup. Being able to assess others in terms of their emotions, thoughts and preferences and the ability to influence these is the second component of self-awareness.

\section{What makes an Individual Self-Aware?}

Avolio \& Gardner (2005) proclaim that self-awareness is the result of an individual being mindful of their own existence, the makeup of such existence and the framework that they operate within. They go on further to point out that like happiness, self-awareness is not a 
destination point but rather a process that continues throughout a person's life upon greater understanding of oneself, potential, experiences, values and beliefs.

An individual who is self-aware can be recognised by their general honesty and ability to realistically assess themselves. Such individuals are able to communicate in an open and accurate manner that is not necessarily confessional or effusive. Self-aware individuals are frank in admittance to failure and often relay their tales quite openly and happily. Goleman (2004) states that 'one of the hallmarks of self-awareness is a self-deprecating sense of humour.' It is also during performance reviews that self-aware individuals can be identified. Individuals who exhibit self-awareness are candid and comfortable in communicating both their strengths and weaknesses. Self-aware individuals welcome constructive criticism; in contrast self-unaware individuals tend to interpret this as the threat or sign of personal failure. Self-confidence is another key trait of self-aware individuals; these individuals have a keen sense of their capabilities and it is much less probable that they will over-extend themselves. This does not however mean that these individuals are not prone to ask for assistance, they do when need be. Self-aware individuals are likely take on calculated risks and will unlikely request challenges that they know cannot be handled by them alone.

An individual's goals and value is understood more with increased levels of self-awareness. A self-aware individual understands and is knowledgeable of his path and why he wants to undertake a journey on such path. A less self-aware individual is prone to making decisions that bring about inner turmoil that treads on buried values. Self-aware individuals make decisions that gel with their values; it is often because of this that they find their work to be energising. (Goleman 2004) Self-aware individuals exhibit high levels of self-consciousness, self-reflection, rumination, insight, creativity, emotional intelligence, empathy, ability to accept critism, self-efficacy, high internal locus of control and the ability to self-monitor and motivate (Morin 2006).

\section{Relationship between Effective Leadership \& Self-Awareness}

The image of leadership has over time undergone vast amount of evolution, Ayman and Korabik (2010) express that the socio-emotional leader is the true leader due to people skills not being contextually dependent as are task skills. According to Hogan and Kaiser (2005) leadership can ultimately be arranged into two categories - the troubadour and academic tradition, although the more popular of the two, the troubadour tradition is a collection of opinions with little facts to support them. Academic tradition however, is a striking contrast which has been referred to by the same authors as a "collection of dependable empirical nuggets". The result of these two trends in leadership literature is that historically personality of a leader has been ignored. Secondly, leadership has been routinely defined by researchers as standing out in a crowd or as holding senior or more authoritative positions in an organisation. Hogan and Kaiser (2005) also proclaim further that team performance is also affected by a leader's personality. Day et al. (2014) have through their research studies found that certain personality traits of an individual is a precursor for effective leadership, that is personality can predict if an individual will be an effective leader. Personality patterns are able to impact the development of leadership development and performance. 
Taylor, Wang and Zhan (2012) stipulate that in order to produce an effective leader, individuals and organisational performance self-awareness is of high importance. Hereford (2015) supports this view by stating that self-awareness is a pivotal component of effective leadership. There have been a fair amount of studies into how "knowing thyself" can lead to effective leadership and successful organisational performance. Goleman (2004) proclaims that in his research senior leaders in organisations often fail to give self-awareness the credit it deserves when considering prospective leaders. He concludes that many executives mistaken honesty for weakness and in turn write-off employees who candidly admit to their short-comings. In essence, senior leaders tend to write-off such individuals and brand them as "not tough enough" to lead others. In general, people however admire and respect honesty - this is essential as leaders are often needed to make decisions that require assessments of both others and their own capabilities (Goleman 2004).

The success and failure of an organization depends on the self-awareness leadership competencies exhibited by its leaders. (Sheldon, Dunning \& Ames 2014). The authors go on to propose that a significant amount of self-awareness is required by leaders in order to drive organizational performance. In respect to leadership, knowing and being true to oneself is fundamental qualities of effectiveness of a leader (Ilies 2005).

According to Baron (2015) the knowledge of self leads to the awareness of self and the two in unison enable us as humans to develop an empathetic and compassionate nature towards those we lead. According to McCarthy and Garavan (1999) there are numerous writers who oppose the contribution that self-awareness makes to career success and effectiveness. However, Martin (2007) points out that it is natural for us as individuals to seek lessons in how great leaders act, that is their actions - he suggests an alternative - this being understanding what goes on within the minds of such leaders when they solve problems involving conflicting ideas. Understanding what goes within the minds of great leaders would become highly difficult if the leader himself is unaware - awareness - in relationship to leadership - is essential to authentic and effective leadership (Avolio \& Gardner 2005).

\section{Research Methodology}

This was a cross-sectional quantitative descriptive study conducted among all the employees working in the management level at SA Homeloans which operates around South Africa. The organization deals fundamentally with providing home loan services to individuals who wish to purchase properties in South Africa, switch their current home loan provider and restructure or refinance their home loans. SA Homeloans currently operates across South Africa with its head offices in La Lucia Ridge, Durban - the organization was established in 2009 and has a national staff complement of 765 . Of those 573 of these staff members were based at the Head Offices in La Lucia ridge Durban, whilst the remaining 192 are based in branches spread across the country. A total of 115 of the staff population are in Management positions ranging from Junior to Executive levels. For the purposes of this study only those individuals in management positions were asked to complete the online questionnaires. Management positions included: Junior Management Level, Middle Management Level, Senior Management Levels and Executive Management Levels. 
Questionnaires were distributed to the 115 members of SA Homeloans management team via an online survey tool called QuestionPro using electronic mail. Subjects were e-mailed a brief overview of the research project and instructions on how to complete the questionnaire (cover letter). Participants were sent follow-up e-mails after 2 weeks and then again after 4 weeks in order to encourage responses.

Permission to conduct research was obtained in the form of an Ethical Clearance Letter from the University of KwaZulu-Natal's ethics committee. Further to this a gate keeper letter was obtained from the organization, SA Homeloans which gave the researcher permission to access and distribute emails to the participants.

\section{Results and Discussion}

A total of 115 participants were invited to participate in the study. A total of 58 completed the online survey resulting response rate of $50 \%$.

\section{Effective Leadership}

More than half of respondents $(53.57 \%)$ rated themselves as having a high level of delegation abilities, and 57.14\% rated themselves as having high levels of adaptability. It was found that $58.93 \%$ of the participants rated themselves as having high levels of consistency. Over half of the participants $(51.92 \%)$ rated themselves as having high levels of enthusiasm, and another $49 \%$ rated themselves as having a high evaluative nature. Regarding communication skills, $48.15 \%$ rated themselves as having high levels of communication skills. High level of emotional intelligence was reported by $44.44 \%$ of the managers. The majority of respondents rated themselves as having high or very high levels in having interest in feedback. Regarding open-mindedness, $44.23 \%$ rated themselves as possessing high levels this characteristic whilst $40.38 \%$ rated themselves to possess very high levels of this characteristic. The majority of respondents $(61.11 \%)$ rated themselves as having high levels of openness to change, whilst $20.37 \%$ rated themselves to possess very high levels of this characteristic. Majority of respondents $(48.15 \%)$ rated themselves as having high levels of organization skills and another $24.07 \%$ rated themselves to possess very high levels of this characteristic. The majority of respondents rated themselves positively with regards to proactivity $(83 \%)$. More than three quarters of the participants reported high level of quite confidence characteristics (82\%). For resourcefulness, it was found that $62.96 \%$ rated themselves as possessing high levels this characteristic whilst $25.93 \%$ rated themselves to possess very high levels of this characteristic. With regards to Respectfulness, 51.85\% rated themselves as possessing high levels this characteristic and $40.74 \%$ rated themselves to possess very high levels of this characteristic. It was found that $48.15 \%$ rated themselves as possessing high levels this characteristic whilst $29.63 \%$ rated themselves to possess very high levels of open-mindedness. 


\section{icalanme}

$4^{\text {th }}$ International Conference on Advanced Research in

Amsterdam, Netherlands

BUSINESS, MANAGEMENT \& ECONOMICS

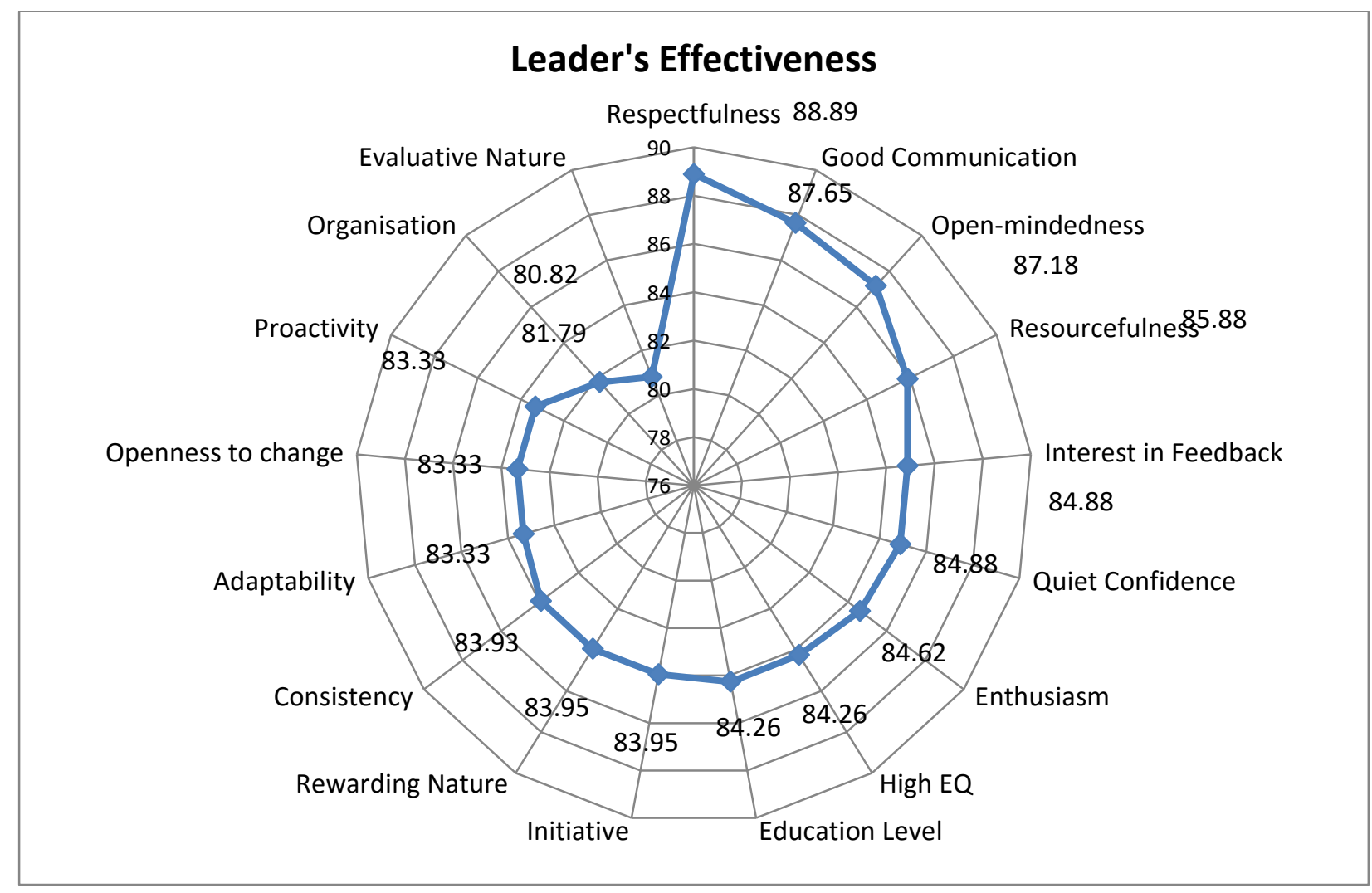

Figure 1: Leader's Effectiveness

\section{Self-Awareness}

To determine the self-awareness, leaders were asked to rate themselves in relation to communicating their strengths and weaknesses, making decisions, emotional intelligence, their interaction with others at the workplace, the level at which they accept themselves, their ability to received criticism, their self-image and their vision for the organization. Most respondents $(64.91 \%)$ felt that they are good at communicating their strengths. Half of the participants $(50.88 \%)$ reported that they are good at decision-making. Regarding emotional intelligence, over a third (35.85\%) rated their Emotional Intelligence (EQ) levels as good. About half of the respondents $(47.17 \%)$ rated their interactions with others in the workplace as very good. For level of self-confidence, $43 \%$ rated their level of self-acceptance as very good. A third of the participants rated their ability to receive criticism as very good. Self-image was found to be good among $40 \%$ of the participants. Regarding vision for the organization, $21 \%$ rated as excellent. The average from all the statement were found to be $70.54 \%$. 


\section{icalanme}

$4^{\text {th }}$ International Conference on Advanced Research in

Amsterdam, Netherlands

BUSINESS, MANAGEMENT \& ECONOMICS

\section{Self-Awareness of Leaders}

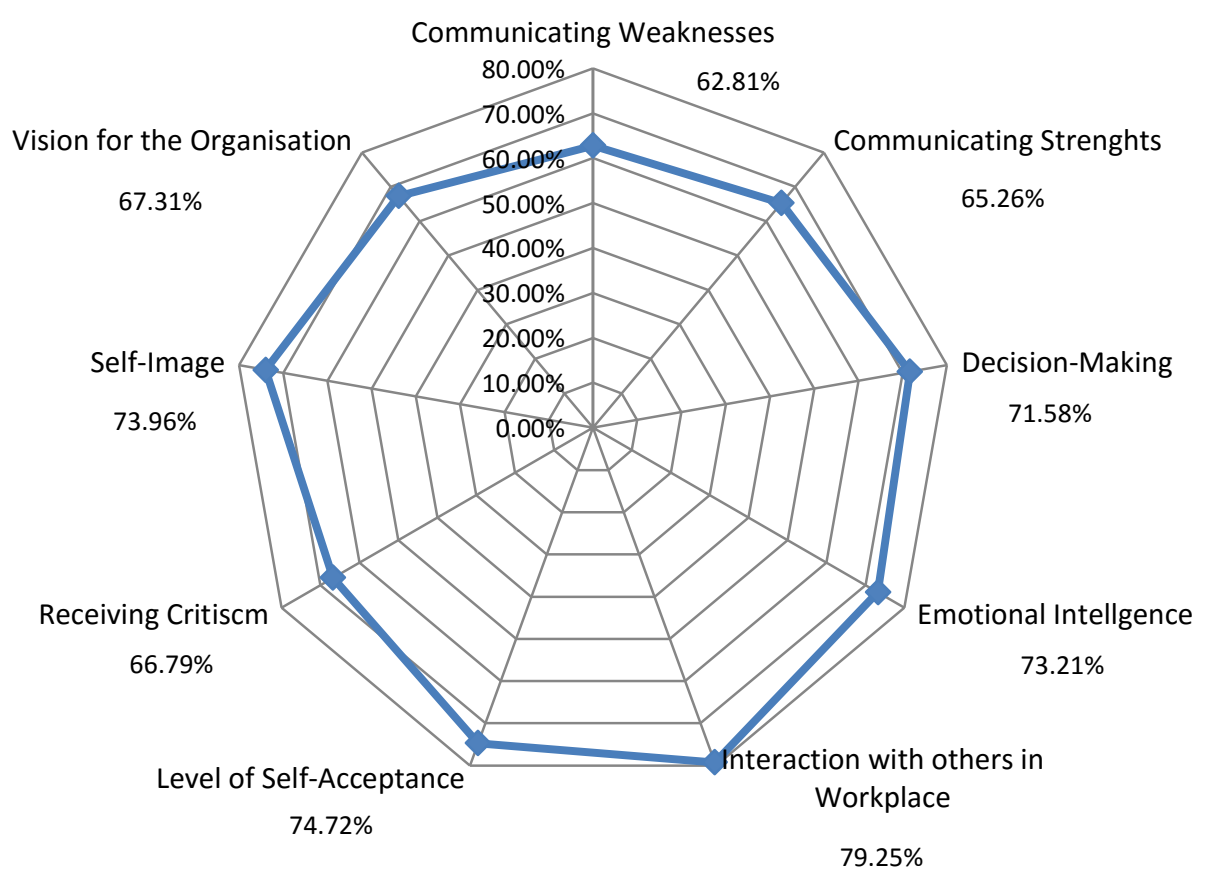

\section{Figure 2: Self-Awareness of Leaders}

Spearman's rank correlation test found no significant relationship ( $r=-0.097)$ between between self-awareness and effective leadership.

\section{Conclusion}

Managers rate themselves as having very good levels of self-awareness. No relationship was found between self-awareness and effective leadership.

\section{Recommedation}

Organizations should not neglect the development of the individual. It appears that most leaders showed a strong public front (by rating themselves as highly effective leaders) but on a personal level did not exhibit the same levels of confidence. The soft skills required for effective leadership are essential, the study concludes that leadership does begin with the person himself and organizations should seek to develop individuals inner strength and awareness in order to develop more effective leadership in organizations. 


\section{References}

Allayarova, ZS, Kalashnikova, TV \& Moiseenko, YA 2015, 'Leadership as a control method in the period of changes', Procedia - Social and Behavioral Sciences, vol 166, pp. 49-47.

Ashley, GC \& Reiter-Palmon, R 2012, 'Self-Awareness and the Evolution of Leaders: The Need for a Better Measure of Self-Awareness', Psychology Faculty Publications, vol 9, pp. $2-17$.

Avolio, BJ \& Gardner, WL 2005, 'Authentic leadership development: Getting to the root of positive forms of leadership', The Leadership Quarterly, vol 16, pp. 315-3383.

Ayman, R \& Korabik, K 2010, 'Why Gender and Culture Matter', American Psychological Association, vol 65, no. 3, pp. 157-170.

Baron, D 2015, The Entrepreneur, [online] available at: <http://www.entrepreneur.com/article/246594> (accessed viewed 3 November 2015)

Burke, RJ \& Cooper, CL 2006, Inspiring Leaders, 1st edn, Routledge, New York.

Datta, B 2015, 'Assessing the Effectiveness of Authentic Leadership', International Journal of Leadership Studies, vol 9, no. 1, pp. 62-75.

Day, DV, Fleenor, JW, Atwater, LE, Sturm, RE \& McKee, RA 2014, 'Advances in leader and leadership development: A review of 25 years of research and theory', The Leadership Quarterly, vol 25, pp. 63-83.

Dorfman, , Javidan, , Hanges, , Dastmalchian, \& House, 2012, 'GLOBE: A twenty year journey into the intriguing world of culture and leadership', Journal of World Business, vol 47, pp. 501-518.

Erden, S 2015, 'Awareness: The effect of group counsellling on awareness and acceptance of self and others', Procedia - Social and Behavioral Sciences, vol 174, pp. 1465-1473.

Goleman, D 2004, 'What makes a Leader?', Best of HBR 1998, 2004, pp. 1-11.

Hernandez, W, Luthanen, A, Ramsel, D \& Osatuke, K 2015, 'The mediating relationship of self-awareness on supervisor burnout and workgroup Civility \& Psychological Safety: A multilevel path analysis', Burnout Research, vol 2, pp. 36-49.

Hogan, R \& Kaiser, RB 2005, 'What we know about Leadership', Review of General Psychology, vol 9, no. 2, pp. 169-180.

Ilies, R 2005, 'Authentic Leadership and Eudaemonic Well-being: Understanding LeaderFollower Outcomes', The Leadership Quarterly, vol 16, pp. 373-394.

Jabr, F 2012, Scientific American, viewed 3 November 2015, <http://www.scientificamerican.com/article/self-awareness-with-a-simple-brain/>. 
Koenig, JA 2011, 'Assessing 21st Century Skills', The National Academic Press, Washington. Leadership, 2015. Leadership. [Online] Available at: http://leadership.uoregon.edu/resources/exercises_tips/skills/leadership_characteristics [Accessed 2 November 2020].

Lichtenstein, BB, Uhl-Bien, M, Marion, R, Seers, A \& Douglas, J 2006, 'Complexity leadership theory: An interactive perspective on leading in complex adaptive systems', Emergence: Complexity and Organization, vol 8, no. 4, pp. 2-12.

Martin, R 2007, 'How Successful Leaders Think', HBR: Essential Guide to Leadership, June 2007, pp. 71-83.

McCarthy, AM \& Garavan, TN 1999, 'Developing self-awareness in the managerial career development process: the value of 360-degree feedback and the MBTI', Journal of European Industrial Training, vol 23, no. 9, pp. 437-445.

Morin, A 2006, 'Levels of consciousness and self-awareness: A comparison and integration of various neurocognitive views', Consciousness and Cognition, vol 15, pp. 358-371.

Obiwuru, TC, Okwu, AT, Akpa, VO \& Nwankwere, IA 2011, 'Effects of Leadership Style on Organisational Performance: A Survey of Selected Small Scale Enterprises in Ikhosi-Ketu Council Development Area of Lagos State, Nigeria', Australian Journal of Business and Management Research, vol 1, no. 7, pp. 100-111.

Parris, DL \& Peachey, JW 2013, 'A Systematic Literature Review of Servant Leadership Theory in Orgnanisational Context', Journal of Business Ethics, vol 113, pp. 377-393.

Sadri, G 2012, 'Emotional Intelligence and Leadership Development', Public Personnel Management, vol 41, no. 3, pp. 535-548.

Schoel, C, Bluemke, M, Mueller, P \& Stahlberg, D 2011, 'When autocratic leaders become an option - uncertainty and self-esteem predict implicit leadership preferences', Journal of Personality and Social Psychology, vol 10, pp. 1-21.

Stone, GA, Russel, RF \& Patterson, K 2004, 'Transformational versus servant leadership: a difference in leader focus', The Leadership \& Organisational Journal, vol 25, no. 4, pp. 349361.

Taylor, SN, Wang, M \& Zhan, Y 2012, 'Going Beyond Self - Other Rating Comparison to Measure Self-Awareness', Journal of Leadership Studies, vol 6, no. 2, pp. 6-31.

Yukl, 1999, 'An Evaluation of Conceptual Weaknessess in Transformational \& Charismatic Leadership Theories', Leadership Quarterly, vol 10, no. 2, pp. 285-305.

Yukl, G 2008, 'How Leaders Influence Organizational Effectiveness', The Leadership Quarterly, vol 19, pp. 708-722. 